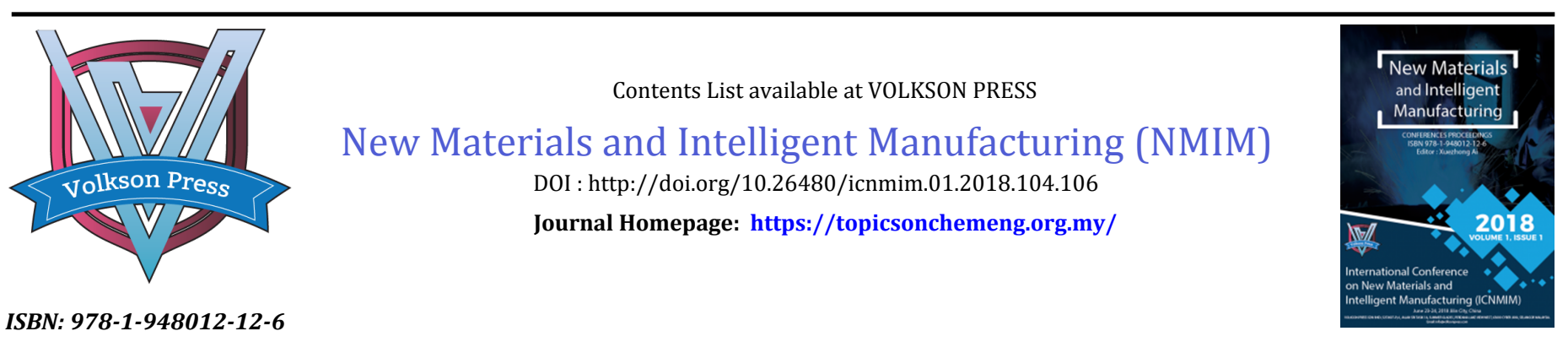

\title{
STUDY ON ORAL ULCER POWDER USING TEMPERATURE-DEPENDENT X-RAY DIFFRACTION TECHNIQUE
}

\author{
Yang Wang1,2, Dayong Lu' ${ }^{*}$ \\ ${ }^{1}$ Key Laboratory for Special Functional Materials in Jilin Provincial Universities, Jilin Institute of Chemical Technology Chengde Street 45, \\ Jilin 132022, China. \\ ${ }^{2}$ College of Chemistry and Pharmaceutical Engineering, Jilin Institute of Chemical Technology, Chengde Street 45, Jilin 132022, China. \\ *Corresponding Author Email: dylu@jlict.edu.cn
}

This is an open access article distributed under the Creative Commons Attribution License, which permits unrestricted use, distribution, and reproduction in any medium, provided the original work is properly cited

\section{ARTICLE DETAILS ABSTRACT}

\section{Article History:}

Received 26 June 2018

Accepted 2 July 2018

Available online 1 August 2018

\begin{abstract}
The temperature-dependent XRD (TD-XRD) technique was used to rapidly detect the three main ingredients (Indigo Naturals (IN), borneol, and alum) of Oral Ulcer Powder (OUP) and impurities introduced in the process of manufacture of OUP. The results show that the three main ingredients of OUP can be monitored by XRD. The hexagonal $\mathrm{Ca}(\mathrm{OH})_{2}$, the rhombohedral $\mathrm{CaCO}_{3}$, and a small amount of $\mathrm{SiO}_{2}$ survive in IN during the process called " $\mathrm{Hit}$

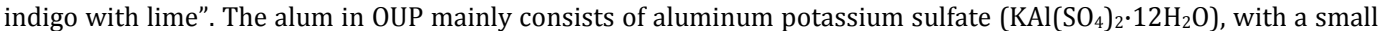
amount of ammonium alum $\left(\mathrm{NH}_{4} \mathrm{Al}\left(\mathrm{SO}_{4}\right)_{2}\right)$. The borneol in OUP gradually disappears with increasing $T$ from 30 to $100^{\circ} \mathrm{C}$, whereas, $\mathrm{NH}_{4} \mathrm{Al}\left(\mathrm{SO}_{4}\right)_{2}$ and rhombohedral $\mathrm{CaCO}_{3}$ survive in OUP. The TD-XRD technique can provide evidence of stability of pharmaceutical preparations and set up a rapid detection method for quality control of OUP.
\end{abstract}

\section{KEYWORDS}

Temperature-dependent X-ray diffraction, Chinese traditional patent medicines, Oral Ulcer Powder, quality control

\section{INTRODUCTION}

Chinese traditional patent medicines (CTPM) are widely used throughout the world because they have definite effect without side effects. The prescription of Oral Ulcer Powder (OUP) (Chinese name kouqiangkuiyangsan) is originally recorded in the Pharmaceutical Standards of the Ministry of Health [1]. OUP is composed of Indigo Naturals (IN), borneol, and alum, witch have been used as heatclearing and detoxifying, relieve pain and inflammation. Chromatography is generally adopted for quality control (QC) of indigo and indirubin in OUP [2-5]. However, the whole structural information of OUP has never been studied. OUP is a complex chemical system, which consists of dozens of independent, but mutually aggregated chemical constituents. If only one or more active components are used as quantitative and qualitative indicators, there is no method to reflect the overall quality of OUP.

New modern analytical methods are needed to be developed for QC of OUP. Fingerprint method has been widely regarded as a method to control the quality of CTPM. Although the composition of CTPM is complex, the XRD technique can effectively monitor the crystalline ingredients of some molecular crystals and inorganic excipients in CTPM and hence becomes an important means of QC of CTPM. XRD had been used to identify fingerprint of some Chinese herbs, analyses on several CTPMs, and QC of pharmaceutical excipients [6-8]. However, XRD still has some localization in QC of OUP because most plant herbs as initial materials have not crystalline structures.

In this work, with the help of International Centre for Diffraction Data (ICDD), the TD-XRD technique was used to study a typical CTPM OUP. From the point of view of material science, the temperature stability of OUP was evaluated, and the whole structural information of OUP was understood. The method of QC of OUP was explored.

\section{EXPERIMENTAL}

The information of oral ulcer powder (OUP), Indigo Naturals, borneol, and alum are listed in Table 1. These samples were crushed and ground in agate mortar for $20 \mathrm{~min}$. The powders were screened with 100 mesh screen to prepare their fines, which were placed in an electronic moistureproof cabinet for XRD measurements. The humidity in the cabinet was kept at $1 \%$ and the storage temperature at $18^{\circ} \mathrm{C}$.

Table 1: Information of Oral ulcer Powder and its ingredients

\begin{tabular}{|c|c|c|c|c|}
\hline Item & $\begin{array}{l}\text { Oral ulcer } \\
\text { Powder }\end{array}$ & $\begin{array}{l}\text { Indigo } \\
\text { Natural } \\
s\end{array}$ & Alum & borneol \\
\hline $\begin{array}{l}\text { Manufactur } \\
\text { er }\end{array}$ & $\begin{array}{l}\text { Beijing } \\
\text { Tongrentang } \\
\text { Pharmaceutic } \\
\text { al Group }\end{array}$ & $\begin{array}{l}\text { Juxing } \\
\text { Indigo } \\
\text { Natural } \\
s \\
\text { Factory, } \\
\text { Xianyou } \\
\text { County, } \\
\text { Fujian } \\
\text { Provinc } \\
\text { e }\end{array}$ & $\begin{array}{l}\text { Hebei Sirui } \\
\text { Pharmaceutic } \\
\text { al Co., Ltd. }\end{array}$ & $\begin{array}{l}\text { Sanjiu } \\
\text { modern } \\
\text { Chinese } \\
\text { medicin } \\
\text { e co., } \\
\text { Ltd. }\end{array}$ \\
\hline Lot Number & 151006 & $\begin{array}{l}160110 \\
7\end{array}$ & 150801 & \\
\hline $\begin{array}{l}\text { Collection } \\
\text { Date }\end{array}$ & $\begin{array}{l}\text { December } 3 \text {, } \\
2016\end{array}$ & $\begin{array}{l}\text { August } \\
6,2017\end{array}$ & $\begin{array}{ll}\text { August } & 6 \text {, } \\
2017 & \end{array}$ & $\begin{array}{l}\text { April 6, } \\
2015\end{array}$ \\
\hline
\end{tabular}

The fines of the above OUP and its ingredients were placed on a metal specimen stage in a sealing chamber. The temperature $(T)$ detected by a thermocouple within the metal specimen stage can accurately reflect the temperature of the metal specimen stage owing to good heat conductivity of metal. Temperature drift error was $\Delta T<1{ }^{\circ} \mathrm{C}$. After these fines were heated to a given $T$ and kept for $30 \mathrm{~min}$, powder XRD spectra were 
measured from 25 to $100{ }^{\circ} \mathrm{C}$ using a DX-2700 X-ray diffractometer equipped with a LTK-450 meso-thermally controlled accessory (Dandong Haoyuan). At each $T$ the XRD data was collected between $5^{\circ} \leq 2 \theta \leq 70^{\circ}$ in steps of $0.02^{\circ}$.

\section{RESULTS AND DISCUSSION}

\subsection{Room-Temperature XRD}

The powder XRD patterns of OUP and three ingredients at room temperature are shown in Fig. 1. Each ingredient exhibits a series of characteristic peaks. The diffraction pattern of OUP is composed of multipeaks of three ingredients IN, alum, and borneol. Vegetation-type IN shows a typical crystalline structure with high-intensity diffraction peaks (Figure 1(b)), which is consistent with partial peaks of OUP. Although alum is also a typical crystal (Figure 1(d)), the main peak at $2 \theta=31.92^{\circ}$ does not match any diffraction peak of OUP, indicating that this kind of alum is not a pharmaceutical excipient in this OUP, but rather ammonium alum $\left(\mathrm{NH}_{4} \mathrm{Al}\left(\mathrm{SO}_{4}\right)_{2}\right)$ with a hexagonal phase structure, as indicated by PDF 230001 (Figure 1(e)).

As a traditional Chinese medicine, borneol is a kind of crystallization that is obtained from the resin and volatile oil. Borneol molecules themselves have no XRD phenomenon, but they can form well-crystallized organic molecular crystals through intermolecular forces (van der Waals' forces or hydrogen bond). Borneol molecules can be arranged periodically along the three-dimensional space and therefore it shows a feature of strong XRD. Some diffraction peaks of OUP contain those of borneol, as denoted in Figure 1(a) [1]. Two XRD peaks at $2 \theta=13.28^{\circ}$ and $25.40^{\circ}$, which appear in the OUP, do not belong to these ingredients (Figure 1).
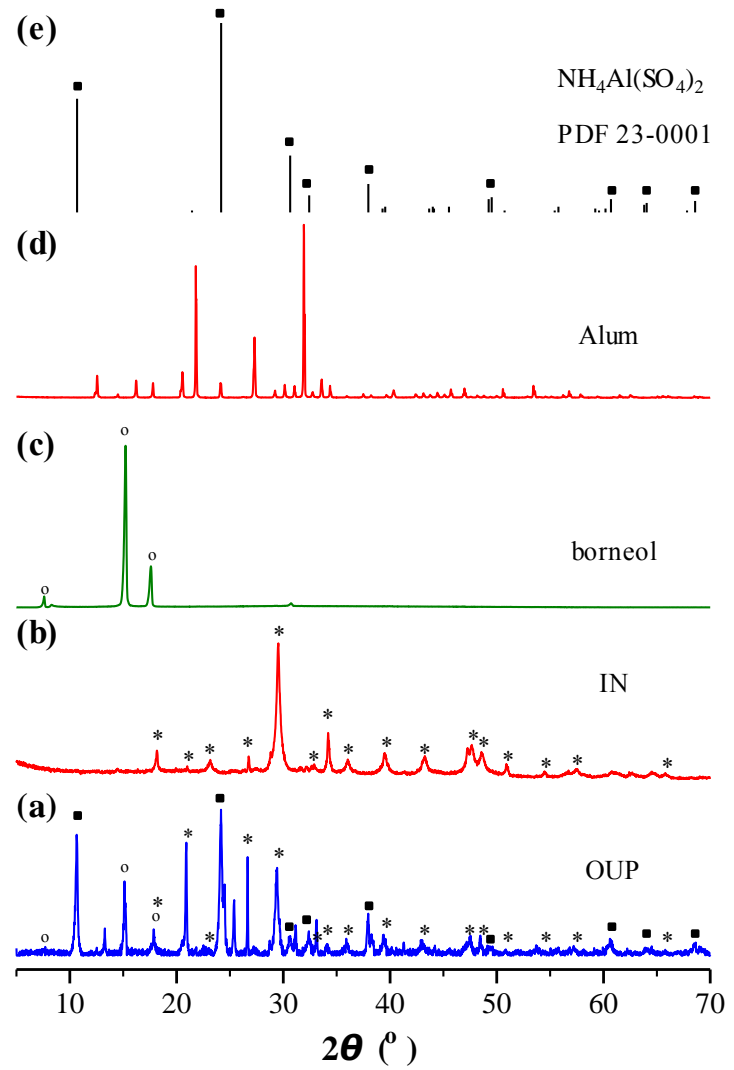

Figure 1: Room-temperature Powder XRD patterns of (a) OUP, (b) IN, (c) borneol, and (d) alum. (e) The simulated XRD pattern of ammonium alum (PDF 23-0001). (c)

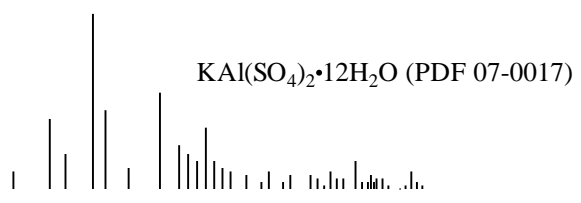

(b)

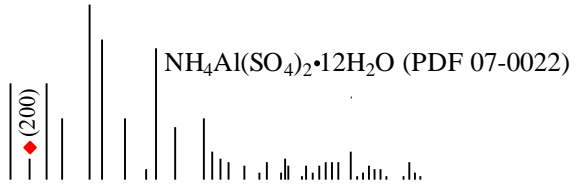

(a)
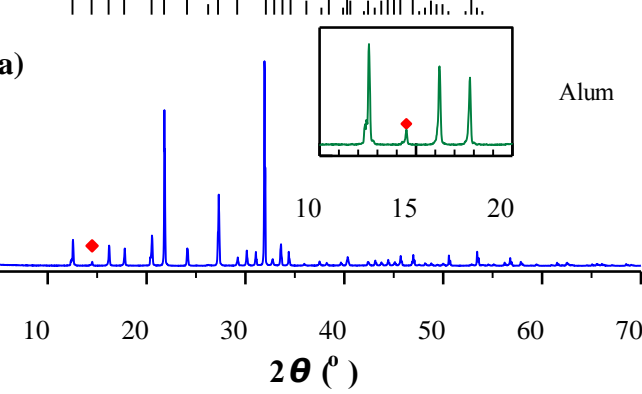

Figure 2: (a) Powder XRD pattern of Alum. The simulated XRD patterns of (b) ammonium alum (PDF 07-0022) and (c) aluminum potassium sulfate (PDF 07-0017).

The XRD spectrum of commercially available alum is shown in Fig. 2(a), in which the simulated XRD patterns of ammonium alum $\left(\mathrm{NH}_{4} \mathrm{Al}\left(\mathrm{SO}_{4}\right)_{2} \cdot 12 \mathrm{H}_{2} \mathrm{O}\right)$ (PDF 07-0022) and aluminum potassium sulfate $\left(\mathrm{KAl}\left(\mathrm{SO}_{4}\right)_{2} \cdot 12 \mathrm{H}_{2} \mathrm{O}\right.$ ) (PDF 07-0017) are provided for comparison. Alum is a crystalline product of sulfate mineral alum [9]. The main composition of our alum sample is identified to be aluminum potassium sulfate. The existence of $2 \theta=14.92^{\circ}$ implies that a small amount of ammonium alum as impurities is mixed in our alum.

The powder XRD pattern of IN is shown in Fig. 3(a), in which the simulated XRD patterns of (b) calcium carbonate (PDF 47-1743) and (c) calcium hydroxide (PDF 76-0571) are provided for comparison. "Hit indigo with lime" is a necessary step in the production of IN. Except for the contained active components such as indigo and indirubin, IN also contained inorganic components such as lime and $\mathrm{SiO}_{2}$. Lime can be divided into calcium oxide $(\mathrm{CaO})$ and slaked lime $\left(\mathrm{Ca}(\mathrm{OH})_{2}\right)$. Addition of lime in IN can not only store carbon dioxide $\left(\mathrm{CO}_{2}\right)$ in soaking solution, but also react with $\mathrm{CO}_{2}$ to transform into calcium carbonate $\left(\mathrm{CaCO}_{3}\right)[10,11]$. In order to determine the source of the diffraction peaks in IN, we simulated the XRD patterns of various $\mathrm{Ca}(\mathrm{OH})_{2}$ and $\mathrm{CaCO}_{3}$ in ICDD. A series of XRD peaks of IN was identified to be composed of those of hexagonal $\mathrm{Ca}(\mathrm{OH})_{2}$ (PDF 760571), rhombohedral $\mathrm{CaCO}_{3}$ (PDF 47-1743), and a small amount of $\mathrm{SiO}_{2}$, as shown in Figure 3.

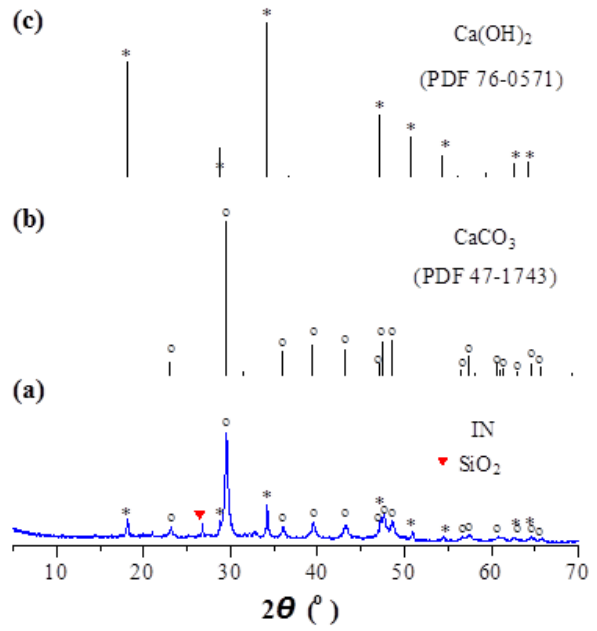

Figure 3: Powder XRD patterns of (a) IN. The simulated XRD patterns of (b) calcium carbonate (PDF 47-1743) and (c) calcium hydroxide (PDF 76-0571). 


\subsection{Temperature-Dependent XRD}

The TD-XRD patterns of OUP are shown in Figure 4. The intensity of the diffraction peaks lowers with increasing $T$ from 30 to $100^{\circ} \mathrm{C}$. The XRD peaks of borneol completely disappears at $T=100{ }^{\circ} \mathrm{C}$, revealing that it is easy to sublimate borneol as the temperature is increased $[12,13]$. Some diffraction peaks survive at $T=100{ }^{\circ} \mathrm{C}$. Two peaks at $2 \theta=10.54^{\circ}$ and $24.02^{\circ}$ arise from $\mathrm{NH}_{4} \mathrm{Al}\left(\mathrm{SO}_{4}\right)_{2}$ and a peak at $2 \theta=29.34^{\circ}$ from rhombohedral $\mathrm{CaCO}_{3}$ in IN.

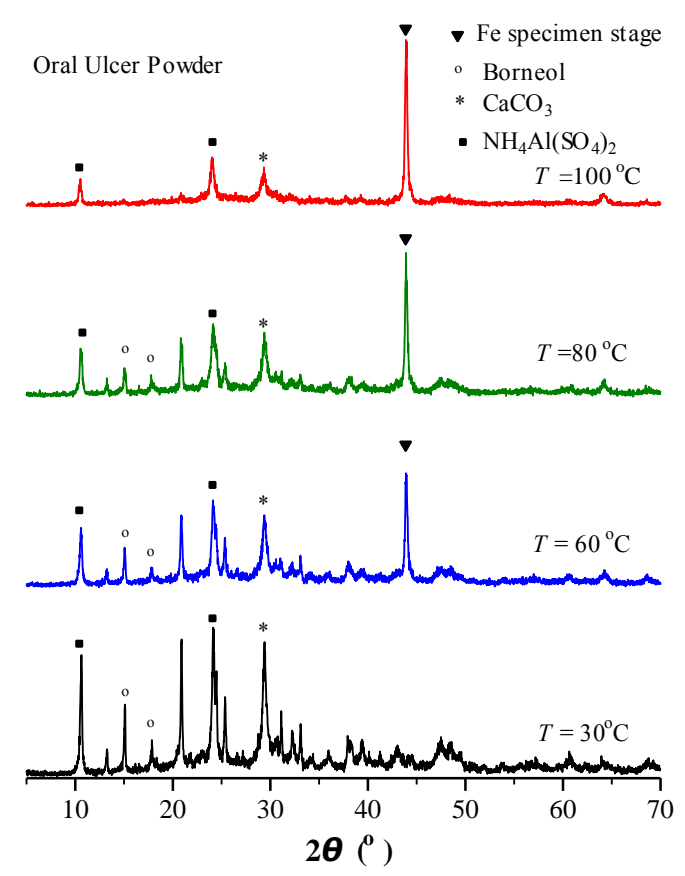

Figure 4: Temperature-dependent XRD patterns of OUP

\section{CONCLUSIONS}

The temperature-dependent XRD technique was used to study a typical Chinese traditional patent medicine - Oral Ulcer Powder (OUP) fabricated by the three ingredients: Indigo Naturals, alum, and borneol. (1) The XRD peaks of Indigo Naturals are identified to arise from hexagonal $\mathrm{Ca}(\mathrm{OH})_{2}$, rhombohedral $\mathrm{CaCO}_{3}$ and a small amount of $\mathrm{SiO}_{2}$. These three impurities are mixed in Indigo Naturals during the process called "Hit indigo with lime".

(2) The XRD spectrum of OUP is composed of those of Indigo Naturals, borneol, and ammonium alum.

(3) Alum in OUP is different with commercially available alum. The latter mainly consists of aluminum potassium sulfate, with a small amount of ammonium alum.

(4) The borneol in OUP gradually disappears with increasing $T$ from 30 to $100^{\circ} \mathrm{C}$, revealing its sublimation nature. Whereas, $\mathrm{NH}_{4} \mathrm{Al}\left(\mathrm{SO}_{4}\right)_{2}$ and rhombohedral $\mathrm{CaCO}_{3}$ survive in OUP.

\section{ACKNOWLEDGEMENT}

This research was financially supported by the project of Changbai Mountain Scholar Distinguished Professor (2015047).

\section{REFERENCES}

[1] National Pharmacopoeia Committee. 2015. Pharmacopoeia of People's Republic of China. Part 1 (p. 505). Beijing: China Medical Science and Technology Press.

[2] Zhao, D.H., Zhang, D.Y., Xie, L.H., Han, R., Zhang, L.G., Li, H. 2017.
Simultaneous determination of indigo and indirubin in Kouqiangkuiyang powders II by HPLC. Chinese Journal of Pharmaceutical Analysis, 37 (7), 1234-1239.

[3] Yan, W., Zhang, N., Liu, J.L. 2009. Simultaneous determination of tryptanthrin, indigo and indirubin in Kouqiangkuiyang powders II by HPLC. Chinese Traditional Patent Medicine, 31 (5), 734-745.

[4] Zhao D.H., Xie L.H., Zhang L.G. 2014. Study on the qualitative identification of Kouqiangkuiyang powders II by TLC. Lishizheng Medicine and Materia Medica Research, 25 (7), 1649-1650.

[5] Yao, J., Liu, B.B., Wang, J.Z. 2012. Determination of indigo and indirubin in Kouchang Mo by HPLC method. Chinese Journal of Pharmaceutical Analysis, 32 (11), 2082-2084.

[6] Gao, X.H. 2005. Methodology Research on the XRD Fingerprint of Chinese Herbs and Establishing of XRD Database of Traditional Chinese Medicine. Sichuan University.

[7] Lu, D.Y., Wang, Y., Chang, W. 2017. Study on Shenyang Hongyao tablet using temperature- dependent X-ray diffraction and electron paramagnetic resonance techniques. Lishizhen Medicine and Materia Medica Research, 28 (2), 384-388.

[8] Chen, X.Q. 2016. PXRD Investigation of 13 Pharmaceutical Excipients and Their Influences on Crystalline Stability of Clopidogrel Bisulfate. Chinese Journal of Pharmaceuticals, 47 (8), 1034-1038.

[9] You, S.X., Liu, S.J., Wu, D.K., Liu, X.H., Lin, R.C. 2011. The comparative study on FTIR fingerprint for alum and calcined alum. Chinese Journal of Pharmaceuticals, 31 (6), 1054-1058.

[10] Zhang, Z.G., Ouyang, R., Li, K., Wang, C.Y., Wang, Q.C. 2002. Study on water grind processing method of Indigo Naturals. Chinese Journal of Pharmaceuticals, 24 (3), 202-204 .

[11] Wen, Q., Yang, M., Xu, R.C., Sun, Q.L., Hu,Y.J. 2004. New conception about the processing of Indigo Naturals. Chinese Traditional Patent Medicine, 26 (2), 116-118.

[12] Ma, L., Zhou, Q.H. 1994. Borneol-determination of loss. Acta Chinese Medicine and Pharmacology, 3, 38-39.

[13] Song, H.T., Guo, T., Zhao, M.H., Zhang, S.H., Li, X., Bi, K.S. 1994. Studies on the physicochemical properties of borneol beta-cyclodextrin inclusion complex. Journal of Shenyang Pharmaceutical University, 19 (4), 249-252.

\section{ABOUT THE AUTHORS}

Professor Dayong Lu was born on July 31, 1967, in Liaoning, China. He earned a bachelor's degree in 1989 and a master's degree in 1996 from Jilin University and a PhD from Yamagata University in 2005. He taught at Jilin Institute of Chemical Technology (JLICT) in China. His research areas are high-permittivity ceramic materials, pharmaceutical analysis and quality control of traditional Chinese medicines, temperature-dependent measuring technology, and inorganic-organic composite materials. He is President of College of Materials Sciences and Engineering, Academic Leader of Materials Science and Engineering discipline, JLICT, Director of Key Laboratory of Special Functional Materials in Jilin Provincial Colleges and Universities. He was awarded New Century Excellent Talents in University, State Education Ministry (2007); Changbai Mountain Scholar Distinguished Professor (2016); and State Department Special Allowance (2015).

Yang Wang was born on March 22, 1992, in Jilin, China. She earned a bachelor's degree from Jilin Institute of Chemical Technology in 2015. She is a postgraduate in Jilin Institute of Chemical Technology. Her research area is pharmaceutical analysis and quality control of traditional Chinese medicines.

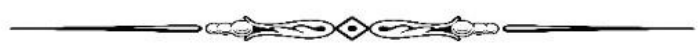

